\title{
Conceptualising attitudes towards brand genuinuity: scale development and validation
}

\author{
Brian't Hart ${ }^{1} \cdot \operatorname{lan} \mathrm{Phau}^{2}$ (1)
}

Revised: 1 January 2022 / Accepted: 4 January 2022 / Published online: 2 February 2022

(c) The Author(s) 2022

\begin{abstract}
This paper aims to conceptualise attitudes towards brand genuinuity by developing and validating a psychometric scale through four studies. Study 1 generates a pool of potential scale items through a review of the literature, thesaurus search, focus groups, and expert surveys. Study 2 confirms the unidimensionality of the scale items using confirmatory factor analysis. Study 3 establishes convergent, discriminant, predictive, and nomological validity. Finally, Study 4 confirms the generalisability of the scale by applying it in a different context. The process resulted in a 5 -item unidimensional scale measuring attitudes towards the brand's genuinuity. The results demonstrated that brand genuinuity is a unique construct, and distinct from related concepts, brand sincerity, and brand heritage. The development and validation of the current scale fill an important gap in the advertising literature. It provides a better understanding of and mechanism to measure attitudes towards brand genuinuity, which could not be measured with previous scales. Likewise, the scale provides important insights for brand managers and will be an important tool for managers to test and confirm the degree to which new advertising material exhibits brand genuinuity.
\end{abstract}

Keywords Brand genuinuity $\cdot$ Brand puffery $\cdot$ Scale development $\cdot$ Scale reliability $\cdot$ Scale validity

\section{Introduction}

Consumers are increasingly calling for brands to be genuine, and yet brands are struggling. The '2021 Global Marketing Trends' report from Deloitte suggests that $66 \%$ of consumers were aware of brands which weren't acting in consumers' interests (Deloitte 2021). Likewise, a report from Stackla suggests that $51 \%$ of consumers feel that more than half of brand-created content doesn't resonate with them. In contrast to this, $92 \%$ of marketers believed that their content was resonating with consumers as 'authentic' ('Stackla Survey Reveals Disconnect Between the Content Consumers Want \& What Marketers Deliver' 2019). These reports show that

Ian Phau

ian.phau@cbs.curtin.edu.au

Brian 't Hart

brian.thart@twu.ca

1 School of Business, Trinity Western University, Langley, Canada

2 School of Marketing, The School of Management and Marketing, Curtin University, GPO Box U1987, Perth, WA 6845, Australia there is a disconnect between brands and consumers, and there is a pressing need to better understand and measure what consumers perceive as 'genuine'.

In the light of this, this paper develops a scale to measure respondents' attitudes towards the genuinuity of a brand. The scale development has been carried out by the use of four separate studies and analysis of 1226 respondents, resulting in the 'attitudes towards brand genuinuity' scale, which consists of 7 items. Brand genuinuity is defined in this paper as 'The degree to which a brand completely expresses their corporate intention without hiding anything, while also exhibiting purity of character'. Many researchers have shown how brand genuinuity is a persuasive and highly effective advertising appeal, and can have a significant influence on consumers' behaviour and purchasing intention of the brand's products (Knapp 2001; Yang et al. 2020).

The scale is produced in response to confusion in the literature about what brand genuinuity is (Geuens et al. 2009; Richardson 1887; Yang et al. 2020). As researchers and businesses have begun to witness the declining effectiveness of brand puffery (i.e. exaggeration which consumers are expected to dismiss) (Preston 1997; Stern and Callister 2020), consumers have become distrustful towards brand 
information, and are increasingly calling for brands to be genuine (Calfee and Ringold 1994; Yang et al. 2020). However, what consumers mean when they call for brands to be genuine is not always clear. While the term 'genuine' is frequently used within both academic and non-academic contexts, its use remains vague and has not previously been properly conceptualised within the literature (Fournier and Avery 2011; Alexander 2009; Akbar and Wymer 2017). Furthermore, there are other terms such as brand sincerity, brand authenticity, and brand honesty, which although they are conceptually different, the literature shows that there is confusion amongst these terms, and they are often used synonymously (Berger 1973; Richardson 1887; Akbar and Wymer 2017; Södergren 2021; Nunes et al. 2021).

The attitudes towards brand genuinuity scale will greatly assist researchers in better understanding what consumers are calling for when they call for brands to be genuine. It will also provide clarification in the literature where the term 'brand genuinuity' is used without much thought as to what it means. A better understanding of brand genuinuity will also assist brand practitioners in understanding how to better position their brands for favourable evaluation by consumers, and understanding how being more genuine might influence consumers attitudes towards the brand.

The paper gives a short background to brand puffery and the emerging need for brands to be genuine. The paper then explores similarities to other terms such as brand sincerity, brand authenticity, and brand honesty, the implications for marketers, and the need for a new scale to be developed. The paper then goes through each of the four studies conducted in detail, and then finally the implications and limitations of the paper are discussed.

\section{Problem development and theoretical underpinnings}

\section{Brand puffery}

The art of painting a brand in a good light is sometimes referred to by researchers as 'puffery' (Sacasas 2001; Punjani, Kumar, and Kadam 2019). Preston (1997) in his research has conceptualised 'puffery' as a harmless means of exaggeration which consumers are expected to dismiss (Hoek and Gendall 2007). Puffery claims are varied in their approach ranging from seemingly factual, such as 'the finest ingredients' to subjective claims that convey prestige and superiority over others brands such as 'the best ever' (Wyckham 1987; Stern and Callister 2020). As noted by Hoek and Gendall (2007), the word puffery is derived from the old English word 'pyffan' which means 'to swell, or seem to swell, as with pride or air'. Hence, the word implies a sense of exaggeration and pride of the firm in their service, products, or other attributes.

Previous studies have indicated the rationale behind such appeals is simply to portray the firm in a positive light, and such appeals are used with the understanding that consumers will discard such claims as harmless exaggeration (Richards 1990; Gao and Scorpio 2011). This assumption by firms and regulators is based on the fact that puffery is a peripheral queue, which with further cognitive processing will be disregarded (Hoek and Gendall 2007). Puffery continues to remain legal in the USA because regulating bodies presume that such claims are not believed by consumers (Gao and Scorpio 2011). However, researchers are beginning to show that puffery is affecting the way consumers perceive a brand, most predominantly by repetition which leads to association (Jacoby and Hoyer 1982; Punjani, Kumar, and Kadam 2019). Haan and Berkey (2002) in their research demonstrate that consumers may be accepting puffs as more literal than intended by the firm, which is leading to consumers having increased distrust in brands (Gao et al. 2012). As noted by Calfee \& Ringold (1994), 70\% of consumers now think that advertising is often untruthful.

\section{The need for brand genuinuity}

In the light of consumers' increasing distrust of brands, a need has arisen for firms and advertising agencies to look at new ways to differentiate themselves from this clutter of puffery and doubtful claims. While thesaurus.com suggests modesty as an antonym for puffery and pride, this may not be a favourable or effective way to differentiate from brand puffery and resonate with consumers. Further, the call for consumers is not for brands to be modest, but rather to be 'genuine'. Therefore, this research focuses on the middle point between puffery and modesty, which this research conceptualises as brand genuinuity (Fig. 1).

Considering research which demonstrates the excessive use of puffery and the overall clutter of advertising (Stern and Callister 2020), brand genuinuity may prove to be an effective way to alleviate this and once again break through this clutter as a genuine brand. As Holt (2002) suggests,

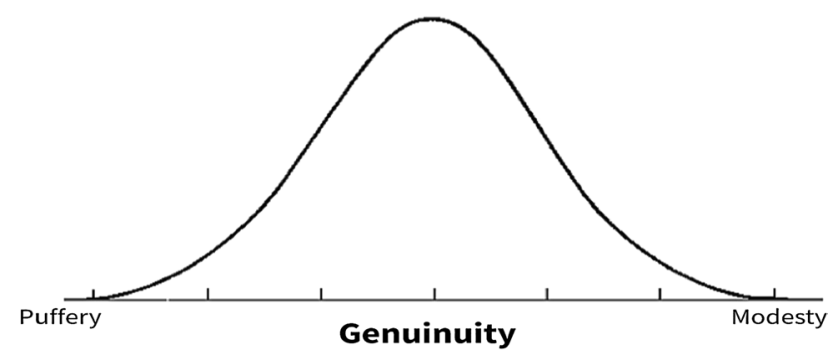

Fig. 1 Illustrating brand genuinuity 
brands need to explore ways to 'peel away the brand veneer', and start to separate the brand from the corporation. Exploring ways to develop brand genuinuity is particularly important for brands as look to try to escape what is sometimes referred to as the 'brand paradox', where consumers perceive the brand as unable to resonate with consumers due to their overarching corporate monetary driving force behind every decision (Gustafsson 2005).

\section{Defining brand genuinuity}

Brand genuinuity has not yet been conceptualised in the literature, however it is often used in different contexts, and other disciplines (exploring the more general term of genuinuity) have provided some insight into what brand genuinuity might encompass. There are a number of terms similar to brand genuinuity including sincerity, authenticity, and honesty, however the literature consistently notes how they are conceptually different. Honesty refers to 'complete disclosure' of all information (Turner, Edgley, and Olmstead 1975; Zakhem 2017), though as noted by Turner, Edgley, \& Olmstead (1975), complete honesty is rarely found amongst friends who consider each other genuine. Sincerity refers to a person being true to their 'station' according to current social expectations (Lionel 1971; Trilling 1971; SánchezArce 2007; Lee and Eastin 2020), however, as noted by Berger (1973), it is quickly becoming a less relevant phenomenon as people increasingly turn to valuing authenticity. Authenticity refers to finding one's 'true self' (Berger 1973), and as Beverland (2005) notes, authentic brands are not boring, rather they 'have soul'. Authentic is relentlessly subjective, based on consumer ideals (Arnould and Price 2000; Athwal and Harris 2018), and consumers use such brands to develop their own identities (M. B. Beverland and Farrelly 2010). While all of these terms are most certainly related to brand genuinuity (Napoli et al. 2014; M. B. Beverland 2005; Brown et al. 2003) and are helpful in defining brand genuinuity, they are conceptually different.

Further review of the above terms including authenticity and honesty suggest that these terms are largely inward focused on the firm and are void of emotion. As noted, authenticity refers to a brand expressing their true self and being true to themselves (Napoli et al. 2014; Wood et al. 2008). Authenticity encourages one to look inward and discover themselves and who they are irrespective of others (including consumers) around them. As noted by Kahn (1992), authenticity is 'the un-pretentious, unmasked, and free expression of internal experience'. Likewise, particularly within a brand context, authenticity is often built on the basis of a brand's heritage (Alexander 2009), yet another component of the brand and their inner being (M. Beverland 2006). Likewise, honesty is inwardly focused. As noted, honesty is defined as a 'complete disclosure' of information (Turner, Edgley, and Olmstead 1975). That is, verbally communicating all of the situationally relevant knowledge, irrespective of others (including consumers) and without consideration for the result (Koslow 2000). Both authenticity and honesty, while having the potential to provide immense value to the consumer, are inherently inward focused by definition. Likewise, since both express without regard for others, including consumers, both are inherently lacking in any relational capacity. A brand which behaves differently in different environments, a common phenomenon in human relationships, would be viewed by the literature as a brand which is acting inauthentic (Sheldon et al. 1997). Therefore, a more relational concept may be needed which allows for such variances in behaviour as a common characteristic of personality, and reflection of an actual relationship between the consumer and the brand (Fleeson and Wilt 2010).

Other literature that explores genuinuity in other contexts propose that it involves some sense of self-awareness and relationship. Within a therapist context, Schnellbacher and Leijssen (2009) suggest that genuineness includes three key dimensions: self-awareness (being aware of one's own experience), self-presence (being emotionally involved in the other person's story), and self-disclosure (being willing to intentionally reveal one's thoughts and values). Genuinuity has also been likened to congruence, particularly in a therapist context. Kolden and Gregory et al. (2011) suggest 'Congruence [genuineness] thus involves mindful self-awareness and self-acceptance on the part of the therapist, as well as a willingness to engage and tactfully share perceptions'. In both examples, genuinuity included a core relational component. It was not limited to being aware of oneself, but rather involved in the other person's (or consumer's) story and being able to effectively engage with that person (or consumer). However, this relational component has largely been missing from any discussion about genuinuity in a brand context, despite relationship marketing only becoming more relevant and important in branding literature (O'Malley 2014; Brodie et al. 1997; Payne and Frow 2017; Gummesson 2017).

The oxford dictionary defines 'genuine' as 'belonging to, or proceeding from the original stock and hence having purity of character'. This definition is largely reflective of the two insights which emerged from the literature. That is, it focuses on the relational component (i.e. belonging to, or proceeding from the original stock) while also focusing on brand characteristics and character (i.e. having purity of character). In line with this, and based on the review of the relevant literature and the insights which emerged, the following definition is proposed for attitudes towards brand genuinuity: 'The degree to which a brand belongs to a community, and hence exhibits purity of character including completely expressing their corporate intention without 
hiding anything'. The definition primarily focuses on the brand's relationship with their community and consumers, while also accounting for purity of character which the literature suggested was an important component of differentiating from brand puffery. Based on this definition, brands might be expected to communicate claims such as 'we are on your side' or 'we are not fancy, but we are cheap'. In other words, brands would be expected to develop their brand genuinuity through their relationships with consumers rather than apart from. The below table (Table 1) provides a summary of the relevant constructs as discussed.

\section{The need for scales}

There is a need to develop a new scale for brand genuinuity. While there is a growing body of literature surrounding brand genuinuity and related terms, there is currently no clear scale developed to measure brand genuinuity. Some researchers have tried to use similar scales, or combined multiple scales (Edberg and Sivertzen 2015). However, none of these provided a sound academic measurement instrument for brand genuinuity. This has led to continued confusion about what these terms refer to (Tatsuki 2006; D. Taylor 1994). For example, many iterations of the Aaker (1997) brand personality scale substitute genuine and sincerity without any explanation. Likewise, more and more papers are being published with varying definitions of brand authenticity, suggesting that some authors may be using the term to refer to concepts which really should be defined as brand genuinuity. Therefore, the first step in contributing to this discussion and better understanding these terms is developing a clear and sound measurement instrument for brand genuinuity. That is the aim of this paper.

\section{Methods and results}

Inline with Churchill's (1979) scale development process, four studies were conducted to develop this scale of 'attitudes towards the brand's genuinuity'. Each study is detailed below including the purpose, method, analysis, and results of the study. The sample characteristics of the four studies are first described.

\section{Study 1: Construct definition and EFA}

\section{Purpose}

The purpose of Study 1 is to generate a set of items which reflect the conceptual and logical variance in the construct (Churchill 1979; Gilliam and Voss 2013; Mrad and Cui 2017). This is otherwise known as determining the construct definition or conceptual domain (Eastman et al. 1999). Schriesheim et al. (1993) and Morgado et al. (2017) note that construct validity issues continue to remain a common problem in scale development. Clearly specifying the domain is imperative to ensuring the resulting items, and final measurement scale adequately captures the conceptual and logical variance present in the construct (Churchill 1979; Mrad and Cui 2017; Gilliam and Voss 2013; Rossiter 2002).This is particularly important in the context of brand genuinuity where there are many closely related terms such as brand authenticity, brand sincerity, and brand honesty, all of which have already been clearly defined and articulated within the literature (Aaker 1997; Napoli et al. 2014; J. P. Taylor 2001). Therefore, as discussed, this paper proposes the following definition for brand genuinuity-'The degree to which a brand completely expresses their corporate intention without hiding anything, while also exhibiting purity of character'.

Using this conceptual definition, a variety of methods were used to generate potential scale items including an extensive literature review, pre-existing scales, thesaurus words, and focus groups, inline with previous studies (Dabholkar et al. 1996; Tian et al. 2001; Mrad and Cui 2017; Cheah and Phau 2015). In conducting a literature review, existing terms, scales, and theories within the genuinuity context were reviewed (Hinkin 1995; Dabholkar et al. 1996). One of the key purposes of the literature review was to explore any previous work which aimed to conceptualise

Table 1 Related constructs to brand genuinuity

\begin{tabular}{lll}
\hline Construct & Definition & Focus \\
\hline Brand Sincerity & $\begin{array}{l}\text { Refers to being true to one's 'station' according to current social expectations (Lionel 1971; } \\
\text { Sánchez-Arce 2007; Trilling 1971) }\end{array}$ & Outward Focused \\
Brand Honesty & $\begin{array}{l}\text { Refers to the 'complete disclosure' of all information (Racelis 2013; Turner, Ronny E and Edgley, } \\
\text { Charles and Olmstead, Glen, 1975; Zakhem 2017) }\end{array}$ & Inward Focused \\
Brand Authenticity & $\begin{array}{l}\text { Focuses on the brand's 'true self' (Berger 1973) and the 'soul' of the brand (Beverland 2006; Napoli } \\
\text { et al. 2014). Authenticity is 'the un-pretentious, unmasked, and free expression of internal experi- } \\
\text { ence' (Kahn 1992) }\end{array}$ \\
$\begin{array}{l}\text { This study proposes that brand genuinuity is 'the degree to which a brand belongs to a community, } \\
\text { and hence exhibits purity of character including completely expressing their corporate intention } \\
\text { without hiding anything' }\end{array}$ & Relationship Focused \\
\hline
\end{tabular}


brand genuinuity or related concepts, and also to understand theories and constructs which brand genuinuity might be a dependent or independent variable of. Exploring crossdiscipline studies was particularly important in the current context where there is very limited research exploring genuinuity within the marketing literature. Based on the items derived from the literature review, a thesaurus search was then conducted to generate further items which reflected genuinuity and related concepts (Wells, Leavitt, and McConville 1971). This is particularly important to ensure that all possible items relating to the construct are included (Soh et al. 2009). The researcher ensured that all items generated had a clear link with the theoretical domain and exhibited content validity (Hinkin 1995), inline with the process adopted by other relevant scale developments ( $\mathrm{Li}$ et al. 2002; Shimul et al. 2019; Flatten et al. 2011; Cheah and Phau 2015).

In addition to the literature review and thesaurus search, 5 focus groups were employed to generate items (Selltiz et al. 1976). Each focus group had 6-10 people and included a range of different scenarios and examples which participants could discuss (Churchill 1979). By having a range of potential areas of discussion, the focus group provided a good platform for allowing the discussion to cover any possible dimensions which genuinuity might include (Churchill 1979). As suggested by Churchill (1979), the critical incidents technique was also used and focus group participants were provided with a number of critical incidents to which they then could reflect and consider what genuinuity might look like in the particular context. The item generation phase continued until no new items emerged. This is consistent with Burns et al. (2008) who terms this as 'sampling the redundancy'. Once items had been generated, the initial pool was reviewed by an expert panel of professors (DeVellis 2003) and unsuitable items were removed (Morgado et al. 2017). Following the above stages, the final item pool generated included the following 31 items (not including those items deemed unsuitable and removed): authentic, caring, charitable, confident, consistent, doesn't change to suit other's opinions, doesn't hide its flaws, doesn't present to be something it is not, down to earth, good motivations, has strong values, honest, listens to customers concerns, motivations are easy to understand, not arrogant, not crushed by other's opinions, not fake, not hypocritical, not manipulative, open, passionate, pure intentions, real, relatable, reliable, similar values to mine, sincere, transparent, truthful, upfront about everything and willing to admit its faults.

\section{Method and analysis}

To test these items, 7-point Likert scales were used as the format of measurement (Carifio and Perla 2008; Gliem and Gliem 2003). Further, items were prefixed with 'I feel the brand is..... For example, rather than simply presenting the item authentic, the item was written as 'I feel the brand is authentic'. This was done inline with previous research on the topic (Homer 1990).

In line with guidelines from DeVellis (2016), the current scale items were then administered to a development sample. This was carried out in a classroom setting in a large Australian university context, with students being the primary respondents. Apart from age, the demographics and characteristics of respondents were representative of the broader population, and that expected of future samples (Espinosa and Ortinau 2016; Ashraf and Merunka 2017; Peterson and Merunka 2014). Special attention was given to ensuring a suitable stimulus was selected for use in this data collection (Malhotra 2006). Through a rigorous selection process, which included conducting a number of focus groups (Vogt, King, and King 2004; Willgerodt 2003), a Tiffany video advertisement was deemed suitable. Tiffany is a world-renowned luxury jewellery brand with strong history in Australia. In addition, they have produced a range of different adverts for different target markets and many consumers will be familiar with the brand. Focus groups suggested that Tiffany was also a brand that might be considered 'genuine'. The data collection resulted in 378 responses after cleaning. Exploratory factor analysis (EFA) is often used as a preliminary step in the scale development process to reduce items, and hence was employed for this study (DeVellis 2003). EFA is a useful mechanism to explore how items load on non-hypothesised factors (Kelloway and Kevin Kelloway 1995; Hurley et al. 1997). It also provides an effective way for researchers to explore the dimensionality of items and purify the scale (Spector 1992), while also ensuring the resulting scale has good internal consistency (Hurley et al. 1997).

\section{Results}

Shapiro-Wilk's test of normality was first conducted, and showed that the collected dataset had no normality issues. The correlation matrix was then generated, and the bivariate correlation (Pearson's r) between each pair of items was checked. Since this is a scale development, items should be expected to have a moderate correlation (Churchill 1979). Therefore, after the correlation matrix was generated, the authors took the average of all correlation scores for each item. Any item with an average of less than 0.3 was removed as this would indicate that the item is measuring something different and it may have negative effects on the factor analysis process. Following item removal, and conducting the exploratory factor analysis, a unidimensional 11 items remained, explaining 58\% variance. The remaining items are shown in Table 2. This is a positive result, however the unidimensionality of the scale now needs to be validated. 
Table 2 Exploratory factor analysis after scale purification

\begin{tabular}{ll}
\hline Item & $\begin{array}{l}\text { Com- } \\
\text { ponent } \\
\text { Loading }\end{array}$ \\
\hline I feel the brand is truthful & .858 \\
I feel the brand is sincere & .835 \\
I feel the brand has pure intentions & .787 \\
I feel the brand is transparent & .772 \\
I feel the brand is honest & .768 \\
I feel the brand has strong values & .701 \\
I feel the brand is upfront about everything & .690 \\
I feel the brand is real & .689 \\
I feel the brand is reliable & .668 \\
I feel the brand has good motivations & .661 \\
I feel the brand is open & .640 \\
Cronbach's $\alpha$ & .930 \\
Variance explained & $58.3 \%$ \\
\hline
\end{tabular}

\section{Study 2: Test of unidimensionality using confirmatory factor analysis}

\section{Purpose}

The purpose of this study is to confirm the unidimensionality of the current scale items using confirmatory factor analysis (CFA) (Hurley et al. 1997), and to purify the scale further if needed. Li et al. (2002) note that ensuring the unidimensionality of the scale is essential since a composite score is normally calculated on the basis of all items in the scale as an unweighted sum (Hattie 1985). Therefore, Confirmatory Factor Analysis is particularly useful after an exploratory factor analysis has been conducted to further test and purify a set of items to ensure both internal consistency (EFA) and goodness of fit (CFA) (Anderson and Gerbing 1984).

\section{Method and analysis}

A new survey containing the remaining 11 brand genuinuity items from Study 1 was created. In line with Churchill (1979), new data were collected for this study, and after cleaning, a total of 407 valid respondents were analysed. Confirmatory factor analysis was then employed to verify the unidimensionality of the scale (Gerbing and Anderson 1988). Further purification was performed where needed in line with the theory of parsimony where fewer items are preferred (Wieland et al. 2018). Finally, content validity was ensured by comparing remaining items with the working definition of the construct (Churchill 1979).

\section{Results}

As part of Study 2, 4 items were removed, leaving a remaining 7 items (Chi-square $=4.081$, df. $=5$, Probability level $=0.536, \mathrm{GFI}=0.996, \mathrm{AGFI}=0.988, \mathrm{CFI}=1.00$, RMSEA $=0.000$ ). The remaining items produced acceptable fit results and also continue to match the character of the overall construct (content / face validity). In addition, the resulting construct has 7 items, which is within the suggested range of 4-8 for unidimensional measurement scales (Mowen and Voss 2008). The current scale is shown below in Fig. 2.

\section{Study 3: Establishing trait/construct validity}

\section{Purpose}

The purpose of Study 3 is to establish trait/construct validity. This to ensure the scale can be stated to be statistically unique from other similar constructs (Churchill 1979). Further, if the construct is too far removed from other relevant constructs, then it may be measuring something different than the authors originally intended. Therefore, this study focuses on testing the different tests of validity, including predictive validity, nomological validity, discriminant validity, and then finally convergent validity (Churchill 1979).
Fig. 2 Attitudes towards brand genuinuity scale items

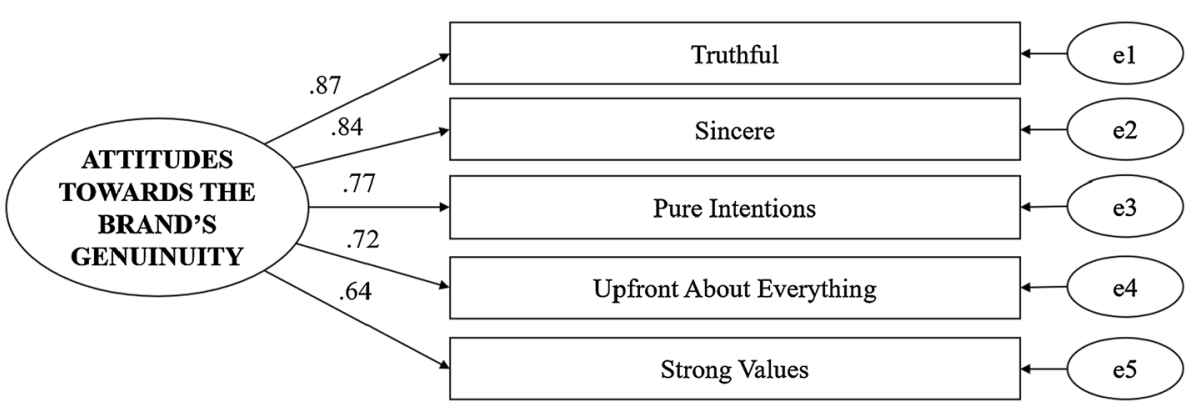


Key studies followed for this include Campbell and Fiske (1959) and Churchill (1979).

\section{Method and analysis}

A new stimulus was developed for the purpose of Study 3. An advert was selected which contained brand genuinuity queues which was selected by the use of 4 focus groups, each which had 8-10 respondents. Respondents were shown a wide range of different adverts, including those that didn't exhibit brand genuinuity queues, which allowed for a more robust discussion about what was considered genuine. This process led to the selection of an advert from the automotive brand Mercedes. A new survey was then developed, which included the proposed brand genuinuity scale items. Additional scales to aid in testing predictive, convergent, and discriminant validity were also included in line with previous literature. In order to test the predictive validity of the proposed brand genuinuity scale, a theoretically relevant construct should be selected (Bechtoldt 1959). Previous research suggests that positive attitudes towards the brand will lead to an intention to buy from that brand (Ajzen and Fishbein 1977). Since the current attitudes towards the brand's genuinuity is an attitudinal scale, the theory suggests that positive attitudes towards the brand's genuinuity will lead to a consumer having a greater intention to purchase from that brand. Therefore, the purchase intention scale from Mackenzie et al. (1986) can be used to test predictive validity. The scale is composed of 3 items, and has been shown to have a reliability alpha of 0.88 (MacKenzie et al. 1986). In order to test predictive validity, a medium split was employed, splitting the data into high and low brand genuinuity. Following this, a t test was conducted to determine if there was a significant difference in purchase intention between the two groups. The purchase intention construct used to determine predictive validity can also be used to determine whether the construct exhibits nomological validity. Nomological validity refers to whether the construct 'behaves as expected with respect to some other construct to which it is theoretically related' (Churchill and Iacobucci 2006). Originally proposed by Cronbach and Meehl (1955), nomological validity focuses specially on how the construct acts within the 'nomological network' within which it exists. It can be ascertained by demonstrating that the patterns of association amongst related empirical measures of a concept correspond to those suggested by related theory (Lynch 1982; Calder et al. 1983). A proposed construct can be said to exhibit nomological validity when it is demonstrated to have frequent and strong correlations with related concepts as proposed by the literature (Whitely 1983; Westen and Rosenthal 2003). Therefore, correlation between brand genuinuity and purchase intention was also tested to determine nomological validity.
Discriminant validity can be ascertained by demonstrating that the proposed construct has weak correlations with related constructs it is theoretically expected to differ from (Peter 1981; Donald T. Campbell 1960). In order for a construct to exhibit discriminant validity, it should be unique from other constructs (O'Leary-Kelly and J. Vokurka 1998). Variance in the measure should be uniquely attributed to the proposed latent variable, and not shared with other related latent constructs (O'Leary-Kelly and J. Vokurka 1998). One method that can be used to test for discriminant validity is to ensure that items within the construct correlate more highly with other items of the same construct than with items from a different latent construct (D. T. Campbell and Fiske 1959; Liu et al. 2012). Conversely, convergent validity refers to the degree to which items within the construct exhibit a stronger correlation then with items from other constructs (Bagozzi 1981). Constructs which have high correlations amongst items are considered to exhibit convergent validity (Liu et al. 2012). Some researchers have suggested that convergent validity can also be demonstrated by exploring correlations with other related latent constructs. (Churchill 1979). In this context, convergent validity is the extent to which the construct correlates with other previously designed scales which measure a related construct. The extent to which the two constructs should correlate is not fixed, as it depends on the nature and underpinning theoretical differences between the two scales. In order to test convergent and discriminant validity, the use of James Gaskin's master validity AMOS tool was used (Gaskin and Lim 2016). This required the inclusion of a number of preexisting related scales which could then be compared with the newly created scale (Churchill 1979). The pre-existing scales chosen for inclusion were 'brand sincerity' (Napoli et al. 2014) which included four measurement items and 'brand heritage' (Napoli et al. 2014) which included six measurement items. James Gaskin's master validity tool tests convergent and discriminant validity by exploring the correlation between items within a scale and between scales, which therefore provides insight how the scale relates to other scales. Based on previous research, brand sincerity is expected to be closely related, almost converging with brand genuinuity while brand heritage is expected to be distinctly different to brand genuinuity. If this is shown to be true, then convergent and discriminant validity can be determined (Gaskin and Lim 2016). Following the completion of the new survey, data were then collected, and 175 respondents were analysed.

\section{Results}

Scales included in this survey for validation purposes (i.e. purchase intention, brand heritage, brand sincerity) all had acceptable Cronbach alpha values $(\alpha=0.938,0.825$, and 
0.810 , respectively). The current proposed brand genuinuity scale also had a good Cronbach alpha value $(\alpha=0.901)$. Predictive (criterion) validity is supported by the results as respondents who had more positive attitudes towards the brand's genuinuity (as measured by the scale currently being developed) had significantly higher intention to purchase the product $(\mathrm{M}=4.76, \mathrm{SD}=1.43)$, compared to respondents who rated the brand as less genuine $(\mathrm{M}=3.33, \mathrm{SD}=1.75)$. Predictive validity is therefore supported. However, Netemeyer et al. (1991) note that when examining the nomological validity, it is important to look at a pattern of results, rather than simply whether one statistic is significant or not (Cronbach and Meehl 1955). A further linear regression showed that the proposed brand genuinuity scale and purchase intention were significantly positively correlated (Pearson's correlation coefficient $=0.521, p=0.000$ ), and brand genuinuity positively predicted purchase intention $(y=0.824 x-0.39)$. As previous authors have suggested, where newly developed scales behave as expected in line with previous literature with related attitudinal and behavioural scales, nomological validity can be asserted. Therefore, since the proposed brand genuinuity scale behaves in line with previous literature, and as expected in relation to other scales (i.e. purchase intention, a behavioural scale), nomological validity has also been strongly demonstrated here. In line with the direction of Churchill (1979), convergent and discriminant validity was then examined. Discriminant and convergent assessments were made in accordance with well-endorsed guidelines from Hair et al. (2010). As shown in Table 3, the reliability for each of the scales is acceptable according to thresholds provided by Hair et al. (2010), with the composite reliability for each of the three scales being higher than 0.7 (brand sincerity $=0.816$, brand heritage $=0.826$, brand genuinuity $=0.903$ ). In line with Hair et al. (2010) and Malhotra and Dash (2016), convergent validity can be asserted, since the average variance extracted (AVE) of the proposed brand genuinuity scale is higher than $0.5(\mathrm{AVE}=0.574)$. Discriminant validity is also demonstrated, since the square root of the AVE is higher than the scale's correlations with other related scales (Fornell and Larcker 1981). While the above method remains the primary way for asserting discriminant validity, some authors have suggested that the average variance extracted (AVE) should also be greater than the maximum shared variance (MSV) (Byrne 2013; 2010; Alumran et al. 2014). The current results also meet these standards (MSV $=0.276)$. Finally, to provide even further support and confirmation of the validity of the proposed scale, in line with theoretical expectations, brand sincerity is shown to be more strongly correlated to the proposed scale $(0.362)$ compared to brand heritage $(0.247)$. Therefore, on all accounts, the results suggest that the current proposed brand genuinuity scale has good predictive, nomological, convergent, and discriminant validity.

\section{Study 4: Generalisability}

\section{Purpose}

It is important that a scale continues to perform well in varying contexts in order to achieve successful adoption in both academic and managerial scenarios (Hair et al. 2010). Therefore, to test the generalisability of the scale, a different stimulus was used in this study. In previous studies, a 'Tiffany \& Co.' advertisement had been used, however, in this study an advert from the luxury automotive brand chain 'Mercedes' was instead used. The advert was chosen since it exhibited similar luxury ques to the Tiffany \& Co advertisement, while still being in a totally different product category. In addition to this, the advertisement was tested across multiple focus groups, and participants rated this advert high on brand genuinuity. Therefore, this advert was deemed appropriate to be used to test the generalisability of the current scale. This study also functions as the final verification of this scale's unidimensionality which CFA is useful in examining (Gerbing and Anderson 1988).

\section{Method and analysis}

Data were collected for this study using panel data. To ensure the data were representative of the broader population, special care was taken to put quotas in place for relevant demographic variables. This ensured that participants ranged in income, educational background, and geographic regions. Results showed that $20.7 \%$ of participants had obtained a postgraduate degree, $42.9 \%$ a bachelor degree and $18 \%$ secondary education. Likewise, ages were varied, with $31.6 \%$ between 18 and $25,36.8 \%$ between 26 and 35 , and $15.4 \%$ between 36 and $45.49 .2 \%$ of participants were female, and $50.8 \%$ were male. Overall, the results showed a very diverse and representative sample. Data collection was done at two different points in time (1 month apart),
Table 3 Convergent and discriminant validity results

\begin{tabular}{llllllll}
\hline & CR & AVE & MSV & $\begin{array}{l}\text { MaxR } \\
(\mathrm{H})\end{array}$ & $\begin{array}{l}\text { ATTBG Pro- } \\
\text { posed Scale }\end{array}$ & $\begin{array}{l}\text { Heritage } \\
\text { Construct }\end{array}$ & $\begin{array}{l}\text { Sincerity } \\
\text { Construct }\end{array}$ \\
\hline ATTBG Proposed Scale & 0.903 & 0.574 & 0.278 & 0.928 & 0.758 & & \\
Heritage Construct & 0.825 & 0.448 & 0.220 & 0.854 & $0.263^{* *}$ & 0.669 & \\
Sincerity Construct & 0.816 & 0.527 & 0.278 & 0.825 & $0.527^{* * *}$ & $0.469^{* * *}$ & 0.726 \\
\hline
\end{tabular}


so as to conduct a test-retest reliability analysis. For the first data collection, 266 responses were analysed. Of these, 104 elected to continue to complete the second part which was sufficient for the test-retest reliability analysis. AMOS 26.0 was used to conduct the Confirmatory Factor Analysis (CFA).

\section{Results}

The proposed brand genuinuity continued to exhibit good reliability under the new respondent conditions (Cronbach's $\alpha=0.43$ ). The results from the CFA are shown in Fig. 3 and exhibited the following fit statistics: Chi-square $=5.95$, df. $=5$, Probability level $=0.311, \mathrm{GFI}=0.984$, AGFI $=0.951$, $\mathrm{TLI}=0.997, \mathrm{RMSEA}=0.036$.

The results from this study showed that the current scale worked well in a completely different product category ( $\mathrm{Hu}$ and Bentler 1999), and therefore was generalisable to other product categories.

Following the confirmatory factor analysis on the first data collection, the results of the second data analysis were also analysed. Specifically, the coefficient alpha was examined and then Pearson's correlation coefficient was tested to check the degree of correlation between the first and second data collection. These tests were done in SPSS version 26.0. Results showed that the coefficient alpha was high for both the test and retest datasets (test $a=0.95$, retest $a=0.91$ ). Likewise, Pearson's correlation coefficient was shown to be 0.697 , with a significance alpha of 0.000 , thus demonstrating a strong and significant relationship between the two test instances. Therefore test-retest reliability could be asserted. Overall, the results from Study 4 demonstrate that the scale exhibits strong reliability and can be generalised in different contexts.

\section{Theoretical implications}

This scale development research is a necessary first step in a better understanding of what constitutes as brand genuinuity, and how brands can better communicate with consumers.
The current paper explores the steps taken to develop a new scale to measure consumers' attitudes towards brand genuinuity. Through the discussed four studies, the current research generates and purifies a set of items (see studies 1 and 2), demonstrates face validity and unidimensionality through the use of CFA (see studies 2 and 4), asserts the proposed scale's predictive/criterion, nomological, convergent, and discriminant validity (see study 3 ) and examines the scales ability to remain effective and functional across different sampling contexts (see study 4). A summary of the process taken to develop this scale is shown in Table 4.

This newly developed scale fills an important gap in the literature as there is currently no scale which has been developed for brand genuinuity (Yang et al. 2020; Knapp 2001; Klein et al. 2001). While there has been a range of different related scales developed in the past, none of them explicitly explored brand genuinuity (Aaker 1997; Fernando 2010). In addition, no scale has been developed which tries to address the phenomenon which contrasts brand puffery (Punjani, Kumar, and Kadam 2019). Therefore, on both accounts, this newly developed scale for attitudes towards the brand's genuinuity fills an important gap in the literature. The new scale provides researchers and academics with a new measure which they can use to conduct further study into brand genuinuity. In terms of methodological significance, this paper provides insight into successful methods for conducting a scale development, and also makes use of new and innovative methods such as the use of James Gaskin's AVE Master Validity tool (Gaskin and Lim 2016). Future studies which aim to develop scales related to brand genuinuity will also be able to use similar methods to successfully develop rigorously tested and ecologically valid scales.

\section{Managerial implications}

The newly developed scale has wide ranging potential managerial applications. Firstly, the scale can be used to check and confirm the degree to which new advertising material (i.e. print adverts, video adverts, labelling) exhibits brand genuinuity. As brands increasingly seek to resonate with
Fig. 3 Study 4 confirmatory factor analysis results

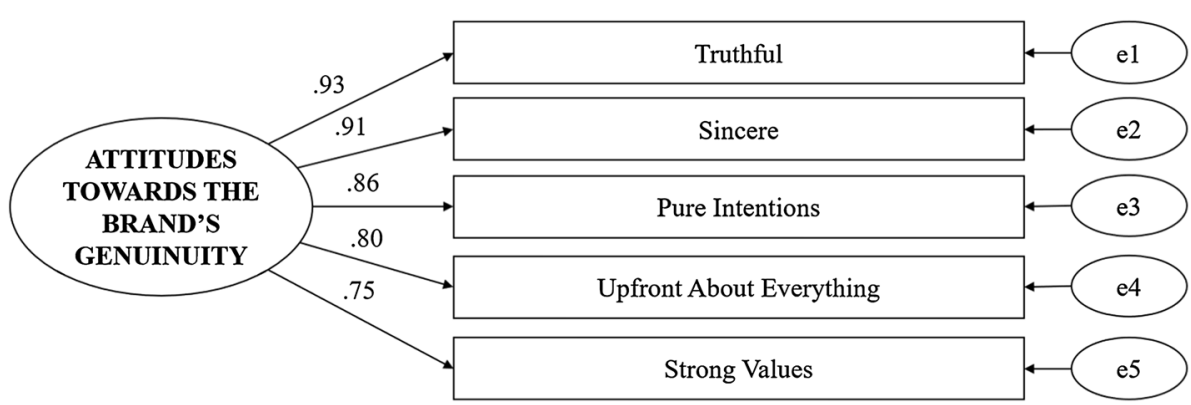


Table 4 Summary of process undertaken to develop the current brand genuinuity scale

\begin{tabular}{|c|c|c|}
\hline Study 1 & $\begin{array}{l}\text { Purpose } \\
\text { Items } \\
\text { Respondents } \\
\text { Stimuli } \\
\text { Key Methods } \\
\text { Results }\end{array}$ & $\begin{array}{l}\text { Generate items and refine item pool } \\
31 \\
n=378 \\
\text { Video advertisement from Tiffany } \\
\text { EFA, Cronbach's reliability analysis } \\
\text { EFA resulted in a unidimensional scale, with } 11 \text { items }(a=0.930)\end{array}$ \\
\hline Study 2 & $\begin{array}{l}\text { Purpose } \\
\text { Items } \\
\text { Respondents } \\
\text { Stimuli } \\
\text { Key Methods } \\
\text { Results }\end{array}$ & $\begin{array}{l}\text { Test unidimensionality and purify items developed in study } 1 \\
11 \text { items } \\
n=407 \\
\text { Video advertisement from Tiffany } \\
\text { CFA with AMOS } 26.0 \\
\text { CFA resulted in } 5 \text { items }(\text { Chi-square }=4.081, \mathrm{df} .=5 \text {, Probability level }=.536, \mathrm{GFI}=.996, \mathrm{AGFI}=.988 \text {, } \\
\text { CFI }=1.00, \text { RMSEA }=.000)\end{array}$ \\
\hline Study 3 & $\begin{array}{l}\text { Purpose } \\
\text { Items } \\
\text { Respondents } \\
\text { Stimuli } \\
\text { Other scales utilised } \\
\text { Key Methods } \\
\text { Results }\end{array}$ & $\begin{array}{l}\text { Validity tests: predictive, nomological, convergent, and discriminant } \\
5 \text { items from study } 2 \\
n=175 \\
\text { Video advertisement from Tiffany } \\
\text { Purchase Intention, Brand Sincerity, Brand Heritage } \\
\text { Median split, } t \text { tests, reliability } a \text {, linear regression, AVE } \\
\text { Predictive validity was demonstrated through the use of a median split and significant } t \text { test, and nomological } \\
\quad \text { validity was proved by linear regression (brand genuinuity influences purchase intention inline with the litera- } \\
\text { ture). Likewise using AVE and correlation scores, convergent, and discriminant validity were asserted }\end{array}$ \\
\hline Study 4 & $\begin{array}{l}\text { Purpose } \\
\text { Items } \\
\text { Respondents } \\
\text { Stimuli } \\
\text { Key Methods } \\
\text { Results }\end{array}$ & $\begin{array}{l}\text { Test generalisability and final verification of unidimensionality } \\
5 \text { items from study } 2 \text { and } 3 \\
\text { Test } n=266 \text {, retest } n=100 \\
\text { Video advertisement from Mercedes (Benz) } \\
\text { CFA with AMOS } 26.0 \text { and correlation } \\
\text { Results showed that the scale continued to maintain reliability }(\mathrm{a}=0.95) \text {, and continued to function even across } \\
\text { varying sample and contexts (Chi-square }=5.95, \mathrm{df} .=5 \text {, Probability level }=.311, \mathrm{GFI}=.984, \mathrm{AGFI}=.951 \text {, } \\
\text { TLI }=.997 \text {, RMSEA }=.036)\end{array}$ \\
\hline
\end{tabular}

consumers, and move away from being seen to use brand puffery, it is expected that brand genuinuity will continue to be an important measure for firms. Having a measure is particularly important for brand genuinuity which many previous researchers have suggested is hard to obtain, mysterious, and potentially can't be manufactured. While brands may view themselves to have genuinuity, consumers who view the brand's advertising stimulus may feel very differently. Therefore, being able to measure the degree to which adverts exhibit the allusive aroma of brand genuinuity is going to be of increasing importance for brands. In addition, as also demonstrated in the predictive (criterion) validity tests, managers can expect consumers who rate a brand highly on brand genuinuity to also be more likely to intend to purchase from that brand.

The newly developed scale's potential uses and managerial applications are expected to become even more relevant as new research and empirical studies are conducted on the basis of this newly developed scale. For example, new studies might be conducted exploring how brand genuinuity relates to brand loyalty, perceptions of brand prestige or luxuriousness and individual product perceptions amongst others. As the body of research relating to brand genuinuity continues to grow, it is expected that brand genuinuity will continue to develop as a common place marketing appeal which enables brands to more effectively resonate with consumers.

\section{Limitations and future research}

While the current paper has gone through a rigorous process to ensure the overall validity and generalisability of the newly developed brand genuinuity scale, there remains opportunity for further research to improve the generalisability and strength of the current scale. Firstly, there remains a need for a better understanding into how brand genuinuity might differ and hence be developed across a wider range of product categories (i.e. utilitarian versus luxury), product types (i.e. goods versus services), and market places contexts (i.e. individual versus group) (W. M. Lim, Phang, and Lim 2020). For example, some research has suggested that brand luxuriousness and brand genuinuity may actually be opposing forces (Ang and Lim 2006), and hence more research into how these dimensions interplay will be useful for both academics and researchers. Further, while this research compares and contrasts brand genuinuity with related terms, there remains other terms in the literature which the newly 
developed scale has not been explicitly tested against, such as brand authenticity. There is much cross-disciplinary research which suggests that these terms are conceptually different (Berger 1973; Richardson 1887; Akbar and Wymer 2017). However, there is a need to better understand how these concepts interplay within a branding context. This research was also largely based on consumers from western countries. However, previous research has suggested that in certain cultures, characteristic traits such as honesty and modesty are more important, and therefore this may also suggest that brand genuinuity may be perceived differently in these cultures. Therefore, it would be useful for future research to explore how brand genuinuity might different across different cultures (both cross-country and within country). Finally, the current scale focuses largely on video advertisements. However, as modern business becomes more fast paced, and increasingly multi channelled, it would be useful to better understand how brand genuinuity might play out when the consumer engages in multi-channel and multi touchpoint interactions (i.e. social media, popup stores) with the brand (Weng Marc Lim et al. 2021).

Through the use of four studies, the current study has conceptualised attitudes towards the brand's genuinuity, and developed and validated a new psychometric scale. As brands continue to explore options for resonating with consumers, researchers are encouraged to explore ways to incorporate the current newly developed scale into their research in the hope that a more fuller and well-developed body of literature can be built around this increasingly important concept.

Funding Open Access funding enabled and organized by CAUL and its Member Institutions. No potential conflict of interest was reported by the authors.

Open Access This article is licensed under a Creative Commons Attribution 4.0 International License, which permits use, sharing, adaptation, distribution and reproduction in any medium or format, as long as you give appropriate credit to the original author(s) and the source, provide a link to the Creative Commons licence, and indicate if changes were made. The images or other third party material in this article are included in the article's Creative Commons licence, unless indicated otherwise in a credit line to the material. If material is not included in the article's Creative Commons licence and your intended use is not permitted by statutory regulation or exceeds the permitted use, you will need to obtain permission directly from the copyright holder. To view a copy of this licence, visit http://creativecommons.org/licenses/by/4.0/.

\section{References}

Aaker, Jennifer L. 1997. Dimensions of brand personality. JMR, Journal of Marketing Research 34 (3): 347-356.
Ajzen, Icek, and Martin Fishbein. 1977. Attitude-behavior relations: A theoretical analysis and review of empirical research. Psychological Bulletin 84 (5): 888.

Akbar, Mohammad Muzahid, and Walter Wymer. 2017. Refining the conceptualization of brand authenticity. Journal of Brand Management 24 (1): 14-32.

Alexander, Nicholas. 2009. Brand authentication: Creating and maintaining Brand Auras. European Journal of Marketing 43 (3/4): 551-562.

Alumran, Arwa, Xiang-Yu. Hou, Jiandong Sun, Abdullah A. Yousef, and Cameron Hurst. 2014. Assessing the construct validity and reliability of the parental perception on antibiotics (PAPA) scales. BMC Public Health 14 (January): 73.

Anderson, James C., and David W. Gerbing. 1984. The effect of sampling error on convergence, improper solutions, and goodness-of-fit indices for maximum likelihood confirmatory factor analysis. Psychometrika 49 (2): 155-173.

Ang, Swee Hoon, and Elison Ai Ching. Lim. 2006. The influence of metaphors and product type on brand personality perceptions and attitudes. Journal of Advertising 35 (2): 39-53.

Arnould, Eric J., and Linda L. Price. 2000. Questing for self and community. The Why of Consumption: Contemporary Perspectives on Consumer Motives, Goals and Desires 1 (1): 140.

Ashraf, Rohail, and Dwight Merunka. 2017. the use and misuse of student samples: An empirical investigation of European marketing research. Journal of Consumer Behaviour 16 (4): 295-308.

Athwal, Navdeep, and Lloyd C. Harris. 2018. Examining how brand authenticity is established and maintained: The case of the reverso. Journal of Marketing Management 34 (3-4): 347-369.

Bagozzi, R.P. 1981. An examination of the validity of two models of attitude. Multivariate Behavioral Research 16 (3): 323-359.

Bechtoldt, Harold P. 1959. Construct validity: A critique. The American Psychologist 14 (10): 619-629.

Berger, Peter L. 1973. Sincerity and authenticity in modern society. The Public Interest 31: 81.

Beverland, Michael B. 2005. Crafting brand authenticity: the case of luxury wines. Journal of Management Studies 42 (5): 1003-1029.

Beverland, Michael. 2006. The 'Real Thing': Branding authenticity in the luxury wine trade. Journal of Business Research 59 (2): 251-258.

Beverland, Michael, and Francis Farrelly. 2010. The quest for authenticity in consumption: Consumers' purposive choice of authentic cues to shape experienced outcomes. The Journal of Consumer Research 36 (5): 838-856.

Brodie, Roderick J., Nicole E. Coviello, Richard W. Brookes, and Victoria Little. 1997. Towards a paradigm shift in marketing? An examination of current marketing practices. Journal of Marketing Management 13 (5): 383-406.

Brown, Stephen, Robert V. Kozinets, and John F. Sherry. 2003. Teaching old brands new tricks: Retro branding and the revival of brand meaning. Journal of Marketing 67 (3): 19-33.

Burns, Karen EA., Mark Duffett, Michelle E. Kho, Maureen O. Meade, Neill KJ. Adhikari, Tasnim Sinuff, and Deborah J. Cook. 2008. A guide for the design and conduct of self-administered surveys of clinicians. CMAJ Canadian Medical Association Journal 179 (3): 245-252.

Byrne, Barbara M. 2013. Structural equation modeling with Mplus: Basic concepts, applications, and programming. Routledge.

Calder, Bobby J., Lynn W. Phillips, and Alice M. Tybout. 1983. Beyond external validity. The Journal of Consumer Research 10 (1): 112-114.

Calfee, John E., and Debra Jones Ringold. 1994. The 70\% majority: Enduring CONSUMER BELIEFS ABOUT ADVERTISING. Journal of Public Policy \& Marketing 13 (2): 228-238. 
Campbell, Donald T. 1960. Recommendations for APA test standards regarding construct, trait, or discriminant validity. American Psychologist 15: 546-553.

Campbell, D.T., and D.W. Fiske. 1959. Convergent and discriminant validation by the multitrait-multimethod matrix. Psychological Bulletin 56 (2): 81-105.

Carifio, James, and Rocco Perla. 2008. Resolving the 50-year debate around using and misusing Likert scales. Medical Education 42 (12): 1150-1152.

Cheah, Isaac, and Ian Phau. 2015. Conceptualising consumer economic nationalistic tendencies: Scale development and validation. The International Review of Retail, Distribution and Consumer Research 25 (3): 313-331.

Churchill, Gilbert A. 1979. A paradigm for developing better measures of marketing constructs. JMR, Journal of Marketing Research 16 (1): 64-73.

Churchill, Gilbert A., and Dawn Iacobucci. 2006. Marketing research: Methodological foundations. New York: Dryden Press.

Cronbach, L.J., and P.E. Meehl. 1955. Construct validity in psychological tests. Psychological Bulletin 52 (4): 281-302.

Dabholkar, Pratibha A., Dayle I. Thorpe, and Joseph O. Rentz. 1996. A measure of service quality for retail stores: Scale development and validation. Journal of the Academy of Marketing Science 24 (1): 3.

Dabholkar, Pratibha A., Dayle I. Thorpe, and Joseph O. Rentz. 2016. Scale development: Theory and applications. SAGE Publications.

Deloitte. 2021. "2021 Global Marketing Trends.” https://www2.deloi tte.com/content/dam/insights/us/articles/6963_global-marke ting-trends/DI_2021-Global-Marketing-Trends_US.pdf.

DeVellis, Robert F. 2003. Scale development: Theory and applications. Applied social research methods series. Bickman, L and DJ Rog. Thousand Oaks, Calif.: SAGE Publications

Eastman, Jacqueline K., Ronald E. Goldsmith, and Leisa Reinecke Flynn. 1999. Status consumption in consumer behavior: Scale development and validation. Journal of Marketing Theory and Practice 7 (3): 41-52.

Edberg, E., and O. Sivertzen. 2015. Keeping it real while selling out: How to increase customer-based brand equity by utilizing brand authenticity. http://www.diva-portal.org/smash/record. jsf?pid=diva2: 824161 .

Espinosa, Jennifer A., and David J. Ortinau. 2016. Debunking Legendary Beliefs about Student Samples in Marketing Research. Journal of Business Research 69 (8): 3149-3158.

Fernando, Mario. 2010. Corporate social responsibility in the wake of the Asian Tsunami: Effect of time on the genuineness of CSR initiatives. European Management Journal 28 (1): 68-79.

Flatten, Tessa C., Andreas Engelen, Shaker A. Zahra, and Malte Brettel. 2011. A measure of absorptive capacity: Scale development and validation. European Management Journal 29 (2): 98-116.

Fleeson, William, and Joshua Wilt. 2010. The Relevance of Big Five Trait content in behavior to subjective authenticity: Do high levels of within-person behavioral variability undermine or enable authenticity achievement? Journal of Personality 78 (4): $1353-1382$

Fornell, Claes, and David F. Larcker. 1981. Evaluating structural equation models with unobservable variables and measurement error. Journal of Marketing Research. https://doi.org/10.1177/00222 4378101800104.

Fournier, Susan, and Jill Avery. 2011. The uninvited brand. Business Horizons 54 (3): 193-207.

Gao, Zhihong, and Elaine A. Scorpio. 2011. Does puffery deceive? An empirical investigation. Journal of Consumer Policy 34 (2): 249-264.
Gao, Zhihong, Na. Li, and Elaine A. Scorpio. 2012. Perception of puffery in advertising: Investigating the China-US differences. Asia Pacific Journal of Marketing and Logistics 24 (2): 179-198.

Gaskin, J., and J. Lim. 2016. Master validity tool. AMOS Plugin In: Gaskination's StatWiki.

Gerbing, David W., and James C. Anderson. 1988. An updated paradigm for scale development incorporating unidimensionality and its assessment. JMR, Journal of Marketing Research 25 (2): 186-192.

Geuens, Maggie, Bert Weijters, and Kristof De Wulf. 2009. A new measure of brand personality. International Journal of Research in Marketing 26 (2): 97-107.

Gilliam, David A., and Kevin Voss. 2013. A proposed procedure for construct definition in marketing. European Journal of Marketing 47 (1/2): 5-26.

Gliem, Joseph A., and Rosemary R. Gliem. 2003. Calculating, interpreting, and reporting Cronbach's Alpha reliability coefficient for Likert-type scales. In . Midwest Research-to-Practice Conference in Adult, Continuing, and Community Education.

Gummesson, Evert. 2017. From relationship marketing to total relationship marketing and beyond. Journal of Professional Services Marketing 31 (1): 16-19.

Gustafsson, Clara. 2005. Brand trust and authenticity: The link between trust in brands and the consumer's role on the market. ACR European Advances. http://www.acrwebsite.org/volumes/13773/eacr/ vol7/E-07.

Haan, Perry, and Cal Berkey. 2002. A study of the believability of the forms of puffery. Journal of Marketing Communications 8 (4): 243-256.

Hair, J. F., W. C. Black, B. J. Babin, and R. E. Anderson. 2010. Confirmatory factor analysis. Multivariate data analysis, 7 th $\mathrm{Ed}$, Pearson Education, Inc.: Upper Saddle River, NJ, USA, 600-638.

Hattie, John. 1985. Methodology review: Assessing unidimensionality of tests and ltenls. Applied Psychological Measurement 9 (2): 139-164.

Hinkin, Timothy R. 1995. A review of scale development practices in the study of organizations. Journal of Management 21 (5): 967-988.

Hoek, Janet, and Philip Gendall. 2007. "An Examination of Puffery's Effects on Consumers." In Proceedings of The Australian and New Zealand Marketing Academy Conference. University of Otago, Dunedin.

Holt, Douglas B. 2002. Why do brands cause trouble? A dialectical theory of consumer culture and branding. The Journal of Consumer Research 29 (1): 70-90.

Homer, Pamela M. 1990. The mediating role of attitude toward the ad: Some additional evidence. JMR, Journal of Marketing Research 27 (1): 78-86.

$\mathrm{Hu}, \mathrm{Li}$.-tze, and Peter M. Bentler. 1999. Cutoff criteria for fit indexes in covariance structure analysis: Conventional criteria versus new alternatives. Structural Equation Modeling: A Multidisciplinary Journal 6 (1): 1-55.

Hurley, Amy E., Terri A. Scandura, Chester A. Schriesheim, Michael T. Brannick, Anson Seers, Robert J. Vandenberg, and Larry J. Williams. 1997. Exploratory and confirmatory factor analysis: Guidelines, issues, and alternatives. Journal of Organizational Behavior: THe International Journal of Industrial, Occupational and Organizational Psychology and Behavior 18 (6): 667-683.

Jacoby, Jacob, and Wayne D. Hoyer. 1982. Viewer miscomprehension of televised communication: Selected findings. Journal of Marketing 46 (4): 12-26.

Kahn, William A. 1992. To be fully there: Psychological presence at work. Human Relations 45 (4): 321-349.

Kelloway, E. Kevin., and E. Kevin Kelloway. 1995. Structural equation modelling in perspective. Journal of Organizational Behavior. https://doi.org/10.1002/job.4030160304. 
Klein, Marjorie H., Gregory G. Kolden, Jennifer L. Michels, and Sarah Chisholm-Stockard. 2001. Congruence or genuineness. Psychotherapy Theory, Research, Practice, Training 38 (4): 396-400. https://doi.org/10.1037/0033-3204.38.4.396.

Knapp, Duane. 2001. Building and maintaining genuine brands in the world of medicine. Journal of Medical Marketing 1 (4): 289-298.

Kolden, Gregory G., Marjorie H. Klein, Chia-Chiang. Wang, and Sara B. Austin. 2011. Congruence/Genuineness. Psychotherapy 48 (1): $65-71$.

Koslow, Scott. 2000. Can the truth hurt? How honest and persuasive advertising can unintentionally lead to increased consumer skepticism. The Journal of Consumer Affairs 34 (2): 245-267.

Lee, Jung Ah, and Matthew S. Eastin. 2020. I like what she's \#endorsing: The impact of female social media influencers' perceived sincerity, consumer envy, and product type. Journal of Interactive Advertising 20 (1): 76-91.

Li, Hairong, Steven M. Edwards, and Joo-Hyun. Lee. 2002. Measuring the intrusiveness of advertisements: Scale development and validation. Journal of Advertising 31 (2): 37-47.

Lim, W.M., C.S.C. Phang, and A.L. Lim. 2020. The effects of possession-and social inclusion-defined materialism on consumer behavior toward economical versus luxury product categories, goods versus services product types, and individual versus group marketplace scenarios. Journal of Retailing and Consumer Services 56: 102158.

Lim, Weng Marc, Sahil Gupta, Arun Aggarwal, Justin Paul, and Priyanka Sadhna. 2021. How do digital natives perceive and react toward online advertising? Implications for SMEs. Journal of Strategic Marketing, 1-35.

Lionel, Trilling. 1971. Sincerity and authenticity. Oxford: Oxford University Press.

Liu, Liping, Chan Li, and Dan Zhu. 2012. A new approach to testing nomological validity and its application to a second-order measurement model of trust. Journal of the Association for Information Systems 13 (12): 4.

Lynch, John G. 1982. On the external validity of experiments in consumer research. The Journal of Consumer Research 9 (3): 225-239.

MacKenzie, Scott B., Richard J. Lutz, and George E. Belch. 1986. The role of attitude toward the ad as a mediator of advertising effectiveness: A test of competing explanations. JMR, Journal of Marketing Research 23 (2): 130-143.

Malhotra, Naresh K. 2006. Questionnaire design and scale development. The handbook of marketing research: Uses, Misuses, and Future Advances, 83-94.

Malhotra, Naresh K., and Satyabhusan Dash. 2016. Marketing research: An applied orientation. Pearson.

Morgado, Fabiane F. R., Juliana F. F. Meireles, Clara M. Neves, Ana C. S. Amaral, and Maria E. C. Ferreira. 2017. Scale development: Ten main limitations and recommendations to improve future research practices. Psicologia Reflexão e Crítica 30 (1): 3.

Mowen, John C., and Kevin E. Voss. 2008. On building better construct measures: Implications of a general hierarchical model. Psychology and Marketing 25 (6): 485-505.

Mrad, Mona, and Charles Chi Cui. 2017. Brand addiction: conceptualization and scale development. European Journal of Marketing 51 (11/12): 1938-1960.

Napoli, Julie, Sonia J. Dickinson, Michael B. Beverland, and Francis Farrelly. 2014. Measuring consumer-based brand authenticity. Journal of Business Research 67 (6): 1090-1098.

Netemeyer, Richard G., Srinivas Durvasula, and Donald R. Lichtenstein. 1991. A cross-national assessment of the reliability and validity of the CETSCALE. Journal of Marketing Research. https://doi.org/10.2307/3172867.
Nunes, Joseph C., Andrea Ordanini, and Gaia Giambastiani. 2021. The concept of authenticity: What it means to consumers. Journal of Marketing 85 (4): 1-20.

O'Leary-Kelly, Scott W., and Robert J. Vokurka. 1998. The empirical assessment of construct validity. Journal of Operations Management 16 (4): 387-405.

O’Malley, Lisa. 2014. Relational marketing: Development, debates and directions. Journal of Marketing Management 30 (11-12): $1220-1238$.

Payne, Adrian, and Pennie Frow. 2017. Relationship marketing: Looking backwards towards the future. Journal of Professional Services Marketing 31 (1): 11-15.

Peter, J. Paul. 1981. Construct validity: A review of basic issues and marketing practices. JMR, Journal of Marketing Research 18 (2): 133-145

Peterson, Robert A., and Dwight R. Merunka. 2014. Convenience samples of college students and research reproducibility. Journal of Business Research 67 (5): 1035-1041.

Preston, Ivan L. 1997. Regulatory positions toward advertising puffery of the uniform commercial code and the federal trade commission. Journal of Public Policy \& Marketing 16 (2): 336-344.

Punjani, Krunal K., V. V. Ravi Kumar, and Sanjeev Kadam. 2019. Trends of puffery in advertising--a bibliometric analysis. Benchmarking: An International Journal. https://www.emerald.com/ insight/content/doi/https://doi.org/10.1108/BIJ-01-2019-0022/ full/html?casa_token=jpfuYJY2BFYAAAAA:DQYnHWECZ7 KXEeznA97sInqW07mMhAHacu6U7U2WZxCfUUquYM YiK46o-kMXaPNIwJb-32FInVhrnx4LeO61m2NMyim6u SbTYOLRZ5MjLchDDXGIeM0.

Racelis, A. (2013). Developing a virtue ethics scale: Exploratory survey of Philippine managers. Asian Journal of Business and Accounting, 6(1). https://ajba.um.edu.my/article/download/2664/ 865

Richards, Jef I. 1990. A" New and Improved" view of puffery. Journal of Public Policy \& Marketing 9 (1): 73-84.

Richardson, E.C. 1887. Authenticity and genuineness. Journal of the Society of Biblical Literature and Exegesis 7 (1): 84-89.

Rossiter, John R. 2002. The c-oar-se procedure for scale development in marketing. International Journal of Research in Marketing 19 (4): 305-335.

Sacasas, Rene. 2001. The 'Pizza Wars.' Journal of the Academy of Academy of Marketing Science 29 (2): 205-206.

Sánchez-Arce, Ana María. 2007. 'Authenticism,' or the Authority of Authenticity. Mosaic: A Journal for the Interdisciplinary Study of Literature, 139-55.

Schnellbacher, Jutta, and Mia Leijssen. 2009. The significance of therapist genuineness from the client's perspective. Journal of Humanistic Psychology 49 (2): 207-228.

Schriesheim, Chester A., Kathleen J. Powers, Terri A. Scandura, Claudia C. Gardiner, and Melenie J. Lankau. 1993. Improving construct measurement in management research: Comments and a quantitative approach for assessing the theoretical content adequacy of paper-and-pencil survey-type instruments. Journal of Management 19 (2): 385-417.

Selltiz, Claire, Lawrence S. Wrightsman, and Stuart Wellford Cook. 1976. Research Methods in Social Relations. Rinehart and Winston: Holt.

Sheldon, Kennon M., Richard M. Ryan, Laird J. Rawsthorne, and Barbara Ilardi. 1997. Trait self and true self: Cross-role variation in the big-five personality traits and its relations with psychological authenticity and subjective well-being. Journal of Personality and Social Psychology 73 (6): 1380-1393.

Shimul, Anwar Sadat, Ian Phau, and Michael Lwin. 2019. Conceptualising luxury brand attachment: Scale development and validation. Journal of Brand Management 26 (6): 675-690. 
Södergren, Jonatan. 2021. Brand authenticity: 25 Years of research. International Journal of Consumer Studies 45 (4): 645-663.

Soh, Hyeonjin, Leonard N. Reid, and Karen Whitehill King. 2009. Measuring trust in advertising. Journal of Advertising 38 (2): 83-104.

Spector, Paul E. 1992. Summated Rating Scale Construction: An Introduction Sage. Newbury Park, CA. http://ocw.usu.ac.id/course/ download/1270000027-psikometri/psk_132_slide_summated_ rating_scale_construction.pdf.

"Stackla Survey Reveals Disconnect Between the Content Consumers Want \& What Marketers Deliver.” 2019. February 20, 2019. https://stackla.com/resources/press-releases/stackla-survey-revea 1s-disconnect-between-the-content-consumers-want-what-marke ters-deliver/.

Stern, Lesa A., and Mark Callister. 2020. Exploring variations of hyperbole and puffery in advertising. Journal of Current Issues \& Research in Advertising 41 (1): 71-87.

Tatsuki, Donna. 2006. What is authenticity. The Language Teacher 16 (5): 17-21.

Taylor, David. 1994. Inauthentic authenticity or authentic inauthenticity. TESL-EJ 1 (2): 1-11.

Taylor, John P. 2001. Authenticity and sincerity in tourism. Annals of Tourism Research 28 (1): 7-26.

Tian, Kelly Tepper, William O. Bearden, and Gary L. Hunter. 2001. Consumers' need for uniqueness: Scale development and validation. The Journal of Consumer Research 28 (1): 50-66.

Trilling, Lionel. 1971. Authenticity and the modern unconscious. Commentary 52 (3): 39.

Turner, Ronny E., Charles Edgley, and Glen Olmstead. 1975. Information control in conversations: Honesty is not always the best policy. Kansas Journal of Sociology 1: 69-89.

Vogt, Dawne S., Daniel W. King, and Lynda A. King. 2004. Focus groups in psychological assessment: Enhancing content validity by consulting members of the target population. Psychological Assessment 16 (3): 231-243.

Wells, William D., Clark Leavitt, and Maureen McConville. 1971. A Reaction profile for TV commercials. Journal of Advertising Research. http://psycnet.apa.org/record/1972-28018-001.

Westen, Drew, and Robert Rosenthal. 2003. Quantifying construct validity: Two simple measures. Journal of Personality and Social Psychology 84 (3): 608-618.
Whitely, Susan E. 1983. Construct validity: Construct representation versus nomothetic span. Psychological Bulletin 93 (1): 179-197.

Wieland, Andreas, Florian Kock, and Alexander Josiassen. 2018. Scale purification: State-of-the-art review and guidelines. International Journal of Contemporary Hospitality Management 30 (11): 3346-3362.

Willgerodt, Mayumi Anne. 2003. Using focus groups to develop culturally relevant instruments. Western Journal of Nursing Research 25 (7): 798-814.

Wood, Alex M., P. Alex Linley, John Maltby, Michael Baliousis, and Stephen Joseph. 2008. The authentic personality: A Theoretical and empirical conceptualization and the development of the authenticity scale. Journal of Counseling Psychology 55 (3): 385-399.

Wyckham, Robert G. 1987. Implied superiority claims. Journal of Advertising Research 27 (1): 54-63.

Yang, Jing, Camilla Teran, Ava Francesca Battocchio, Ebbe Bertellotti, and Shannon Wrzesinski. 2020. Building brand authenticity on social media: The impact of Instagram Ad model genuineness and trustworthiness on perceived brand authenticity and consumer responses. Journal of Interactive Advertising 22: 1-39.

Zakhem, Abe Joseph. 2017. Honesty and integrity in advertising. Handbook of Virtue Ethics in Business and Management, 1037-46.

Publisher's Note Springer Nature remains neutral with regard to jurisdictional claims in published maps and institutional affiliations.

Brian't Hart is a lecturer in Trinity Western University. His research interests includebranding and advertising issues.

Ian Phau is John Curtin Distinguished Professor at Curtin University, Australia. His researchinterests include luxury branding, country image, brand counterfeiting and tourism. 